\title{
Article \\ Perinatal outcome of induced and spontaneous pregnancies of primiparous women aged 35 or over
}

\author{
Z. Kozinszky ${ }^{\mathrm{a}}$, H. Orvos ${ }^{\mathrm{a}}$, M. Katona ${ }^{\mathrm{b}}$, T. Zoboki ${ }^{\mathrm{a}}$, A. Pál ${ }^{\mathrm{a}}$, L. Kovács ${ }^{\mathrm{a}, *}$ \\ ${ }^{a}$ Department of Obstetrics and Gynecology, University of Szeged, Szeged, Hungary \\ ${ }^{\mathrm{b}}$ Department of Pediatrics, University of Szeged, Szeged, Hungary
}

Received 6 July 2001; received in revised form 3 October 2001; accepted 10 October 2001

\begin{abstract}
Objectives: To compare the neonatal and maternal morbidity data associated with induced or naturally conceived pregnancies of primiparous women aged 35 years and older. Methods: We recruited primiparous women aged 35 years and older, who delivered between January 1995 and December 2000. The outcomes of the induced $(n=62)$ and naturally conceived $(n=132)$ pregnancies were compared. The Fisher exact test was used for univariate analysis in order to compare the delivery and pregnancy characteristics in the two groups. Results: Cesarean section featured with a 0.76 times lower prevalence among the induced pregnant women, than among the spontaneous ones, but the difference was not significant statistically. The induced pregnancies were not associated with a significantly higher rate of perinatal complications. Conclusions: Induced pregnancy does not involve a higher risk of maternal complications. The incidence of premature newborns and intrauterine growth retardation was high in both subgroups, but without a statistically significant difference. (c) 2002 International Federation of Gynecology and Obstetrics. All rights reserved.
\end{abstract}

Keywords: Primiparous women aged 35 or older; Induced and spontaneous pregnancy; Perinatal outcome

\section{Introduction}

In 1958, the Council of the International Federation of Gynecology and Obstetrics recommended an age of 35 years or above should be

\footnotetext{
* Corresponding author. H-6725 Szeged, Semmelweis u. 1., Hungary. Tel.: + 36-62-5454991; fax: +36-62-545711.

E-mail address: kovacs@obgyn.szote.u-szeged.hu (L. Kovács).
}

accepted as the international standard for 'elderly' primipara [1]. In Western European countries there has recently been a shift towards a delay in childbearing [2]. This is explained by the careeroriented lifestyle of women, social and economic reasons and the ever wider application of assisted reproductive techniques. In Hungary too, pregnancy is occurring with increasing frequency after the age of 35 years [3]. This is so despite the fact that pregnancies in primiparous women aged over 
35 have been regarded as high-risk pregnancies because of the elevated risk of chromosomal abnormalities and pregnancy complications.

We are not aware of any published comparison of induced and spontaneous pregnancy amongst elderly primiparas. A higher incidence of cesarean section was detected in this group as compared with primiparas aged 20-29 [4-9], as was an enhanced tendency to toxemia and perinatal mortality [10] and significantly more maternal, intrapartum and neonatal complications [4-9].

It is of importance to know whether the outcome of pregnancy and the delivery among primiparous women aged 35 or above are influenced by the induction of pregnancy.

\section{Materials and methods}

The 10882 neonates delivered from January 1995 to December 2000 in our Department included 207 neonates $(1.9 \%$ of the total) of 194 primiparous mothers aged 35 or over. The study group was divided into two groups: induced pregnancies $(n=62)$ and spontaneous conception ( $n$ =132). Eleven women had twins and one had triplets in the induced group, while four mothers had twins in the spontaneous group.

The antepartum complications examined were: gestational diabetes mellitus, toxemia, myoma, placenta previa, threatened pre-term delivery, meconium-stained amniotic fluid, malpresentation, post-datism, and oligo- and polyhydramnios. The intrapartum complications considered were: premature rupture of the membranes, cephalopelvic disproportion, cesarean section, prolonged labor, and prolonged second stage. Neonatal outcome was analyzed in the two groups. Intrauterine growth retardation was defined as a birth weight below the tenth percentile for that gestational age, according to the sex and to the Hungarian data [3]. Pre-term delivery was taken as birth before the completion of 37 weeks.

Differences in characteristics between the two groups were assessed by the Fisher exact test for categorical variables, and the $t$-test for continuous variables. Odds ratios (O.R.s) and 95\% confidence intervals (C.I.s) were calculated. A probability level $P<0.05$ was considered statistically significant.

\section{Results}

Significantly more multiple pregnancies were delivered in the induced subgroup $(P=0.005$; [O.R.: 5.43, 95\% C.I. (1.60-18.41)] than in the spontaneous group.

Table 1 presents the pattern of pregnancy complications in the surveyed groups. The preva-

Table 1

Pregnancy characteristics

\begin{tabular}{|c|c|c|c|c|c|c|}
\hline & \multicolumn{2}{|c|}{$\begin{array}{l}\text { Induced group } \\
(n=62)\end{array}$} & \multicolumn{2}{|c|}{$\begin{array}{l}\text { Spontaneous group } \\
(n=132)\end{array}$} & \multirow[t]{2}{*}{$P$-value } & \multirow[t]{2}{*}{ O.R. (95\% C.I. $)$} \\
\hline & $n$ & $\%$ & $n$ & $\%$ & & \\
\hline Gestational diabetes mellitus & 4 & 6.5 & 11 & 8.3 & NS & $0.76(0.23-2.49)$ \\
\hline Pre-eclampsia & 13 & 21.0 & 19 & 14.4 & NS & $1.58(0.72-3.45)$ \\
\hline Myoma & 1 & 1.6 & 6 & 4.5 & NS & $0.34(0.04-2.92)$ \\
\hline Placenta previa $^{\mathrm{a}}$ & 1 & 1.6 & 0 & 0 & & \\
\hline Threatened pre-term delivery & 14 & 22.6 & 20 & 15.2 & NS & $1.63(0.76-3.50)$ \\
\hline Meconium-stained amniotic fluid & 11 & 17.7 & 17 & 12.9 & NS & $1.46(0.64-3.34)$ \\
\hline Malpresentation & 10 & 16.1 & 20 & 15.2 & NS & $1.10(0.47-2.46)$ \\
\hline Oligohydramnios & 2 & 3.2 & 8 & 5.8 & NS & $0.54(0.11-2.61)$ \\
\hline Polyhydramnios $^{\mathrm{a}}$ & 0 & 0 & 5 & 3.7 & & \\
\hline Post-datism & 14 & 22.6 & 26 & 19.7 & NS & $1.19(0.57-2.48)$ \\
\hline
\end{tabular}

Abbreviations: NS, not significant; O.R., odds ratio; C.I. confidence interval.

${ }^{a}$ Statistical analysis was not meaningful. 
Table 2

Intrapartum complications

\begin{tabular}{|c|c|c|c|c|c|c|}
\hline & \multicolumn{2}{|c|}{$\begin{array}{l}\text { Induced group } \\
(n=62)\end{array}$} & \multicolumn{2}{|c|}{$\begin{array}{l}\text { Spontaneous group } \\
(n=132)\end{array}$} & \multirow[t]{2}{*}{$P$-value } & \multirow[t]{2}{*}{ O.R. (95\% C.I.) } \\
\hline & $n$ & $\%$ & $n$ & $\%$ & & \\
\hline Premature rupture of the membranes & 21 & 33.9 & 50 & 37.9 & NS & $0.84(0.45-1.58)$ \\
\hline Cephalopelvic disproportion & 5 & 8.1 & 13 & 9.8 & NS & $0.80(0.27-2.36)$ \\
\hline Cesarean section & 29 & 46.8 & 81 & 61.4 & NS & $0.55(0.30-1.02)$ \\
\hline Prolonged labor & 6 & 9.7 & 13 & 9.8 & NS & $0.98(0.35-2.71)$ \\
\hline Prolonged second stage & 6 & 9.7 & 6 & 4.4 & NS & $2.30(0.71-7.45)$ \\
\hline
\end{tabular}

Abbreviations: NS, not significant; O.R., odds ratio; C.I. confidence interval.

lences of gestational diabetes mellitus (6.5\% vs. $8.3 \%)$, pre-eclampsia $(21.0 \%$ vs. $14.4 \%)$, placenta previa $(1.61 \%$ vs. $0 \%)$, threatened pre-term delivery $(22.6 \%$ vs. $15.2 \%)$, meconium-stained amniotic fluid $(17.7 \%$ vs. $12.9 \%)$, post-datism $(22.6 \%$ vs. $19.7 \%)$, myoma ( $1.6 \%$ vs. $4.5 \%$ ), oligohydramnios $(3.2 \%$ vs. $5.8 \%)$ and polyhydramnios $(0 \%$ vs. $3.7 \%$ ) were not significantly different in the two groups.

Table 2 relates to the complications during delivery. The incidences of premature rupture of the membranes (33.9\% vs. $37.9 \%$ ), cephalopelvic disproportion ( $8.1 \%$ vs. $9.8 \%$ ), prolonged labor $(9.7 \%$ vs. $9.8 \%)$ and prolonged second stage $(9.7$ vs. 4.4) were again significantly not different in the two groups. Nor were the frequencies of cesarean section significantly different $(46.8 \%$ vs. $61.4 \%$ ), although the rate here was higher than the overall data for our tertiary center and for Hungary (Hungarian Demographic Yearbook, 2000).

Table 3 provides an overview of the neonatal outcome in the two groups: the mean birth weight of the infants $(3168 \pm 831 \mathrm{~g}$ vs. $2968 \pm 748 \mathrm{~g})$ : the gestational age at delivery $(37.75 \pm 2.97$ weeks vs. $37.43 \pm 2.97$ weeks) and the rates of pre-term birth (25.0\% vs. $18.5 \%)$, intrauterine growth retardation (12\% vs. 8.6\%), an Apgar score at $5 \mathrm{~min}$ $<7(8.3 \%$ vs. $3.0 \%)$. Perinatal mortality did not occur. NICU admission (16.7\% vs. $11.9 \%)$ and congenital malformations $(2.8 \%$ vs. $2.2 \%)$ did not differ significantly in the two groups. The

Table 3

Neonatal outcome

\begin{tabular}{|c|c|c|c|c|c|c|}
\hline & \multicolumn{2}{|c|}{$\begin{array}{l}\text { Induced group } \\
(n=72)\end{array}$} & \multicolumn{2}{|c|}{$\begin{array}{l}\text { Spontaneous group } \\
(n=135)\end{array}$} & \multirow[t]{2}{*}{$P$-value } & \multirow[t]{2}{*}{ O.R. (95\% C.I.) } \\
\hline & $n$ & $\%$ & $n$ & $\%$ & & \\
\hline Gestational age (mean \pm SD) (weeks) & \multicolumn{2}{|c|}{$37.75 \pm 2.97$} & \multicolumn{2}{|l|}{$37.43 \pm 2.97$} & \multicolumn{2}{|l|}{ NS } \\
\hline Birth weight (mean \pm SD) $(\mathrm{g})$ & \multicolumn{2}{|c|}{$3168 \pm 831$} & \multicolumn{2}{|l|}{$2968 \pm 748$} & NS & \\
\hline Pre-term birth & 18 & 25.0 & 25 & 18.5 & NS & $1.47(0.74-2.92)$ \\
\hline Intrauterine growth retardation & 6 & 8.3 & 15 & 11.1 & NS & $0.73(0.27-1.96)$ \\
\hline 5 min Apgar score $<7$ & 6 & 8.3 & 4 & 3.0 & NS & $2.98(0.81-10.92)$ \\
\hline Male newborns & 41 & 56.9 & 76 & 56.3 & NS & $1.03(0.58-1.83)$ \\
\hline Cord blood $\mathrm{pH}>7.20^{\mathrm{a}}$ & $7 / 66$ & 10.6 & $17 / 123$ & 13.8 & NS & $0.74(0.29-1.89)$ \\
\hline NICU admission & 12 & 16.7 & 16 & 11.9 & NS & $1.49(0.66-3.35)$ \\
\hline Congenital malformations & 2 & 2.8 & 3 & 2.2 & NS & $1.26(0.21-7.70)$ \\
\hline Perinatal mortality ${ }^{\mathrm{b}}$ & 0 & 0 & 0 & 0 & & \\
\hline
\end{tabular}

Abbreviations: NS, not significant; O.R., odds ratio; C.I. confidence interval.

${ }^{a}$ Examination was not performed in every case.

${ }^{\mathrm{b}}$ Statistical analysis was not meaningful. 
male:female ratio was higher in the induced group, but not significantly so.

\section{Discussion}

Various authors have reported certain adverse features as regards the outcome of pregnancy among older primiparous women [4-9]. We performed a retrospective study in order to determine the rates of complications of pregnancy and the neonatal outcome among older primiparas in respect of assisted reproductive techniques.

Cesarean section was performed more frequently as compared with the Hungarian and clinical averages. Many other reports have likewise described a significantly higher rate of cesarean delivery among older women. Some authors suggest that the management of labor in older women may differ in some way from that in younger women $[4,8]$. The physician may be more anxious and more careful, but this hypothesis is difficult to evaluate.

The incidence of preterm birth was slightly higher, while that of intrauterine growth retardation was lower in the induced group, but these determinants did not exhibit a significant difference. The rates of premature birth and intrauterine growth retardation were high as compared with the rates for a Hungarian average tertiary center and the recent Hungarian statistical data [3].
Among these older primiparous women, pregnancy following the use of assisted reproduction techniques did not involve a higher risk of neonatal or pregnancy complications as compared with naturally conceived pregnancies.

\section{References}

[1] Barkan SE, Bracken MB. Delayed childbearing: no evidence for increased risk of low birth weight and preterm delivery. Am J Epidemiol 1987;125:101-109.

[2] Demographic Yearbook. New York: United Nations, 2000.

[3] Demographic Yearbook. Budapest: Hungarian Statistical Office, 2000.

[4] Kessler I, Lancet M, Borenstein R, Steinmetz A. The problem of the older primipara. Obstet Gynecol 1980;56:165-169.

[5] Prysak M, Robert PL, Anne K. Pregnancy outcome in nulliparous women 35 years and older. Obstet Gynecol 1995;85:65-70.

[6] Kirz D, Dorchester W, Freeman RK. Advanced maternal age: the mature gravida. Am J Obstet Gynecol 1985;152:7-12.

[7] Edge V, Laros RK. Pregnancy outcome in nulliparous women aged 35 or older. Am J Obstet Gynecol 1993;168:1881-1885.

[8] Berkowitz GS, Skovron ML, Lapinski RH, Berkowitz RL. Delayed childbearing and the outcome of pregnancy. N Engl J Med 1990;322:693-694.

[9] Jolly M, Sebire N, Harris J, Robinson S, Regan L. The risks associated with pregnancy in women aged 35 years or older. Hum Reprod 2000;15:2433-2437.

[10] Tuck SM, Yudkin PL, Turnbull AC. Pregnancy outcome in elderly primigravidae with and without a history of infertility. Br J Obstet Gynaecol 1998;95:230-237. 